\title{
西天山高压-超高压变质带折返过程中的流体活动证据: 高压脉体和异剥钙榴岩
}

\author{
吕增 $\mathbb{1}^{*}$, 张立飞 ${ }^{(1)}$, 陈振宇 ${ }^{(2)}$, 李旭平 ${ }^{3}$, 申婷婷 ${ }^{(1)}$ \\ (1) 造山带与地壳演化教育部重点实验室, 北京大学地球与空间科学学院, 北京 100871; \\ (2) 中国地质科学院矿产资源研究所, 国土资源部成矿作用与资源评价重点实验室, 北京 100037; \\ (3) 山东科技大学地质科学与工程学院, 青岛 266510 \\ * 联系人, E-mail: luzeng@pku.edu.cn
}

2013-05-30 收稿, 2013-06-14 接受, 2013-07-29 网络版发表

国家重点基础研究发展计划(2009CB825007)和国家自然科学基金(41002019, 40730314 和 40821002)资助

\begin{abstract}
摘要 西天山造山带以发育蓝片岩和低温榴辉岩著称, 蓝片岩中的大量榴辉岩相脉体记录了 蓝片岩-榴辉岩相转变时的流体活动. 详细的野外调查发现, 西天山超高压榴辉岩内也发育了 大量的高压脉体, 而与蛇纹岩伴生的榴辉岩则受到了明显的异剥钙榴岩化改造, 这些都是俯 冲带变质作用过程中流体活动的直接证据. 超高压榴辉岩内发育的高压脉体主要有 3 种类型, 分别为绿辉石脉、石英脉和䵢穷石脉, 这些脉体不同程度地切穿了早期的面理. 脉体石榴石 是物理迁移的结果，而其他脉体矿物如榍石、绿辉石、䵢究石、白云石和磷灰石等，是从高 压流体中晶出的. 高压流体对钡元素具有富集作用, 流体成分在时空上存在不均一性. 这些 普遍发育的脉体形成于超高压榴辉岩折返阶段, 表明在减压过程中也可以发生强烈的流体活 动和微量元素迁移. 西天山异剥钙榴岩的原岩年龄为 420 Ma, 异剥钻榴岩化作用发生在折 返阶段( 290 Ma). 在部分异剥钙榴岩化阶段, 流体富集 $\mathrm{Ca}, \mathrm{Si}, \mathrm{Ti}, \mathrm{Mn}, \mathrm{Nb}, \mathrm{Ta}, \mathrm{Zr}$ 和 $\mathrm{Hf}$, 亏损 $\mathrm{Fe}, \mathrm{Mg}, \mathrm{Na}, \mathrm{K}, \mathrm{REE}, \mathrm{Tb}$ 和 $\mathrm{Y}$, 氧逸度高, 流体对岩石的交代作用不彻底, 发育不平衡矿物结 构; 在完全异剥钙榴岩化阶段, 流体富集 $\mathrm{Ca}, \mathrm{Mg}, \mathrm{LREE}, \mathrm{Ni}$ 和 $\mathrm{Cr}$, 亏损 $\mathrm{Fe}, \mathrm{Ti}, \mathrm{Rb}, \mathrm{Ba}, \mathrm{MREE}$ 和 HREE，流体作用强烈，富水流体相的强烈淋滤作用使大部分元素发生迁移.
\end{abstract}

关键词

西天山造山带

高压脉体

金红石 $\mathrm{Zr}$ 温度计

异剥钻榴岩

折返流体

元素迁移
俯冲带深部变质作用过程中的流 (熔) 体活动一 直以来受到地质学家的关注, 因为这关系到板块相 互作用的化学动力学过程, 俯冲带变质作用与岩浆 作用的耦合关系, 以及大陆地壳的增生等一系列基 础地质问题 ${ }^{[1 \sim 3]}$. 因为具有较低的地热梯度, 冷俯冲 作用可以将大量的流体带进地球深部弧岩浆源区的 深度, 这些流体从俯冲板块脱离后通过交代上覆地 幔楔形成弧岩浆。折返至地表的低温/超高压变质岩 最有可能记录这一脱水过程以及相关微量元素的迁 移过程, 因此受到了广泛关注 ${ }^{[2 \sim 4]}$. 西天山造山带的
蓝片岩中发育了大量的榴辉岩相脉体, 被认为是研 究洋壳向下俯冲至 40 70 km 深度时发生蓝片岩-榴 辉岩相转变脱水过程的天然实验室 ${ }^{[5 \sim 8]}$. 最近这几年 陆续在西天山高压变质带不同类型的岩石中发现了 柯石英和其他超高压证据, 证明地壳岩石的最大俯 冲深度超过 $90 \mathrm{~km}$, 远超出蓝片岩相岩石的稳定范

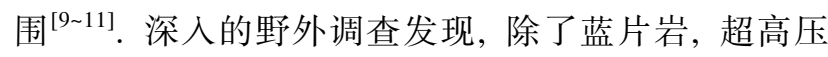
榴辉岩中也发育大量的脉体 ${ }^{[12,13]}$, 蛇纹岩中发育交 代成因的岩石-异剥钻榴岩 ${ }^{[14]}$, 这表明西天山造山带 活动流体(通道型流体和渗透型流体)的广泛性和复

引用格式: 吕增, 张立飞, 陈振宇, 等. 西天山高压-超高压变质带折返过程中的流体活动证据: 高压脉体和异剥钻榴岩. 科学通报, 2013, 58: 21752179

Lü Z, Zhang L F, Chen Z Y, et al. HP vein and rodingite: Evidence of fluid activity during the exhumation of the HP-UHP metamorphic belt of western Tianshan. Chin Sci Bull, 2013, 58: 2175-2179, doi: 10.1360/972013-619 
杂性. 压力是变质流体性质的重要制约因素之一 ${ }^{[15]}$, 俯冲带不同深度的流体具有不同的物理化学性质和 地球化学特征, 其对变质矿物的生长规律、微量元素 的迁移程度和再分配以及同位素体系的扰动程度都 存在差别 ${ }^{[16]}$. 准确识别西天山高压-超高压变质带内 流体的活动期次、来源深度及其地球化学特征差异成 为重要的基础地质问题. 本文总结了西天山超高压 榴辉岩和蛇纹岩中流体活动的证据一一高压脉体和 异剥钙榴岩, 阐述了冷俯冲带折返过程中两种不同 类型流体的地球化学特征.

\section{1 高压脉体的特征及其对流体活动的指示 作用}

西天山超高压榴辉岩内发育的高压脉体主要有 绿辉石脉、石英脉和䵢帘石脉 3 类 ${ }^{[12]}$. 超高压榴辉岩 中的绿辉石多呈纤维状集合体出现, 同一样品的石 榴石变斑晶粒度变化不大, 但在不同的样品间变化 很大. 石榴石粒径较小时一般小于 $0.3 \mathrm{~mm}$, 包体很 少, 以金红石为主, 且环带不明显; 较大石榴石粒径 一般在 2 5 mm 范围变化, 包体较多, 可见金红石、 绿辉石、柯石英及其假象(多晶石英)、硬柱石及其假 象(黝帘石十钠云母)等. 石榴石粒度存在显著差异, 表明进变质过程中成核速率的差异. 我们所研究的 脉体变形都很弱, 组成矿物颗粒粗大, 且自形程度高, 与强烈面理化的围岩榴辉岩的矿物结构特征对比鲜 明(图 1(a)), 局部遭受不同程度的绿片岩相或绿帘角 闪岩相叠加(图 1(c)和(e)). 脉体中浑圆状或残余状石 榴石的成分环带及其包体组合均与围岩中的相似, 表明其是物理迁移的结果(图 1(b))，同时也表明与其 他超高压矿物相比, 石榴石在高压流体中的溶解度 较小. 除石榴石外, 其他脉体矿物如榍石、黝帘石、 白云石、磷灰石以及绿辉石等, 大多为自形晶且含有 丰富的流体包裹体(图 1(f)), 说明这些矿物的形成过 程与围岩不同, 是从高压流体中结晶而来.

白云石是最主要的原生脉体碳酸盐矿物, 颗粒 粗大, 内部可见残余状的方解石或菱镁矿 (图 1(d)), 表明流体的化学成分有阶段性的变化. 一些脉体中 方解石被白云石包裹的结构表明早期流体中镁离子 活度比晚期的低; 而另外一些脉体中菱镁矿被白云 石包裹的结构则表明早期流体中钻离子活度较低. 脉体中的含钛矿物相为金红石和榍石，一般在手标 本尺度都可以识别, 前者更为普遍. 绿辉石脉中可见
粗大自形榍石与其他脉体矿物在结构上达到平衡, 但包裹残余状金红石(图 1(c)), 这说明晚期流体的 $\mathrm{Ca}$ 离子活度比早期的高, 金红石很可能通过反应 $\mathrm{Rt}+\mathrm{Ca}$, $\mathrm{Si}_{\mathrm{fluid}}=\mathrm{Ttn}$ 生成榍石 ${ }^{[17]}$. 一些脉体的多硅白云母发育 了明显的环带结构(图 1(e)), 核部和边部 $\mathrm{BaO}$ 含量分 别为 $1.0 \mathrm{wt} \%$ 和 $1.7 \mathrm{wt} \%$ (wt \%, 质量分数, 余同).

上述特征表明，西天山超高压榴辉岩内发育的 脉体(流体)具有多阶段演化的特点, 存在时空不均一 性，因此这些超高压榴辉岩经历了多次的不同程度 的开裂-愈合生长过程, 与 John 等人 ${ }^{[7]}$ 的研究结果一 致. 通过对脉体中原生流体包裹体的 LA-ICPMS 半 定量分析(图 1(f)), 确定高压流体中的钡离子含量较 其他微量元素具有明显的升高. 和围岩片岩相比, 脉 体中的多硅白云母中钡含量都有不同程度的提高, 这说明高压流体对钡元素具有明显的富集作用，且 流体中的钡含量在时空上存在不均一性, 与前面的 分析结果一致.

\section{2 高压脉体形成的条件}

金红石是高压-超高压变质岩中的常见副矿物, 随着金红石 $\mathrm{Zr}$ 温度计的完善及其良好的适用性 ${ }^{[18]}$, 其对俯冲带变质岩 $P-T$ 轨迹的约束作用也越来越受 到重视 ${ }^{[19]}$. 为量化高压脉体和围岩榴辉岩的形成条 件差异, 我们对西天山哈布腾苏和科布尔特地区的 一些榴辉岩及其脉体中金红石的赋存状态及其成分 特征进行了系统的研究 ${ }^{[13]}$.

围岩榴辉岩中的金红石既可以包裹体形式存在 于石榴石、绿辉石或角闪石中，也可与其他基质矿物 共生. 基质金红石常部分退变为榍石, 具不规则形态, 有时形成串珠状或集合体状．榴辉岩中的金红石常 含有榍石、钠云母、多硅白云母、角闪石、绿辉石、 石榴石、石英、绿帘石、方解石和绿泥石等包裹体，局 部可见较多的微米-亚微米级的锆石包体. 脉体金红 石粒度不一, 有些为长达数厘米的柱状自形晶体, 有 些则为小于 $1 \mathrm{~mm}$ 的它形粒状颗粒. 脉体金红石包体 数量相对较少, 可见石英、方解石、绿帘石、绿泥石、 榍石和锆石等包体.

围岩榴辉岩中单个颗粒金红石 $\mathrm{Zr}$ 含量平均值分 别为 $34 \pm 5,33 \pm 11,26 \pm 7,36 \pm 17,22 \pm 6$ 和 $40 \pm 17 \mathrm{ppm}$ $\left(1 \mathrm{ppm}=1 \mu \mathrm{g} \mathrm{g}^{-1}\right.$, 余同), 个别样品中出现异常高但变 化明显的 Zr 含量(可高达 749 2046 ppm). 电子探针分 析显示, $\mathrm{Zr}$ 异常高的金红石中均含有微米-亚微米级的 

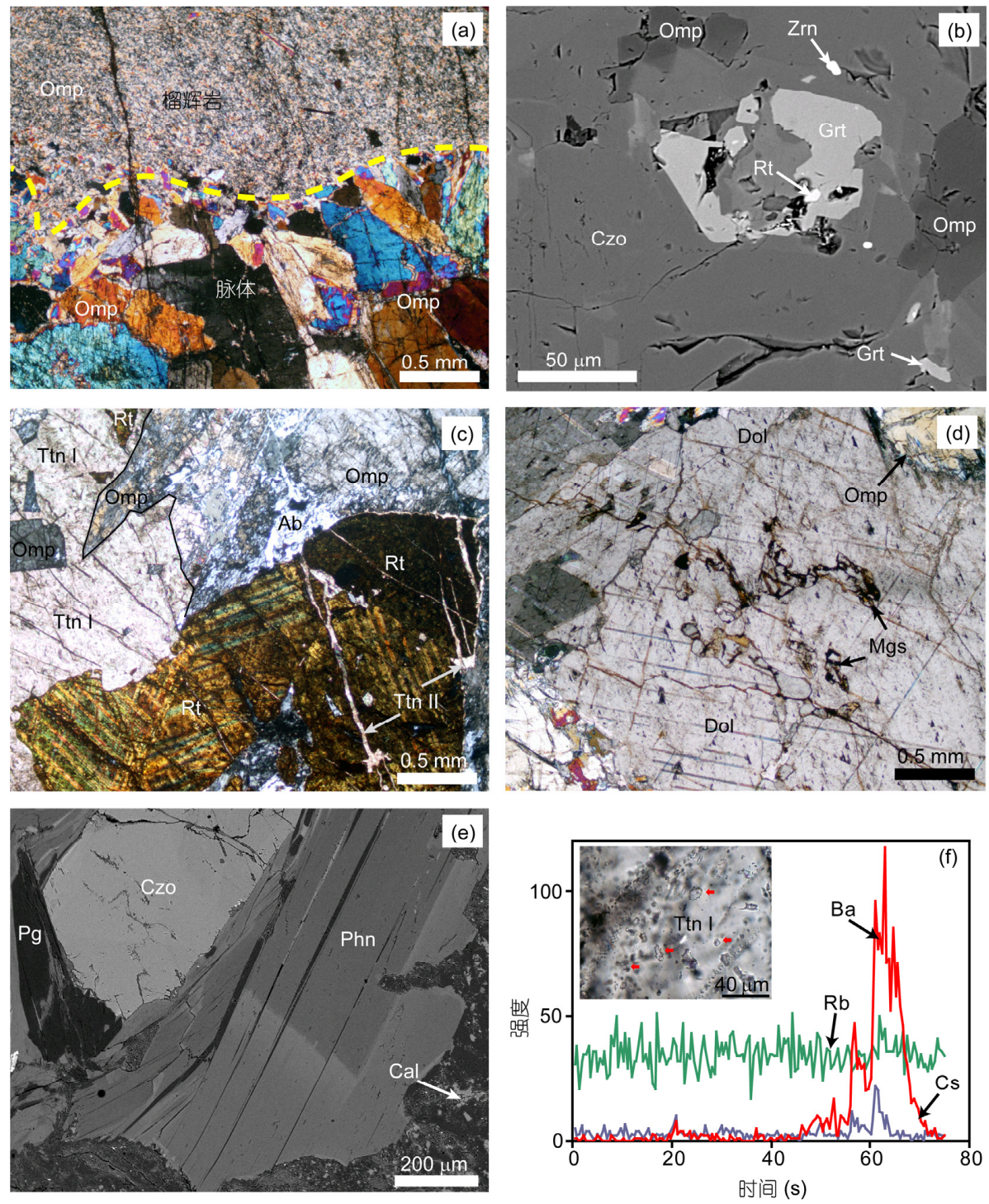

图 1 西天山超高压榴辉岩中的高压脉体显微结构

据文献[12]修改. (a) 脉体与围岩的界限; (b) 残余状的脉体石榴石; (c) 脉体金红石和榍石(局部受到绿片岩相改造, 形成 Ab+TtnII); (d) 脉体白 云石及其包体; (e) 发育环带的脉体多硅白云母(局部碳酸盐化); (f) 脉体榍石的原生流体包裹体成分特点(LA-ICPMS 分析). Ab, 钠长石; Cal, 方解石; Czo, 斜黝帘石; Dol, 白云石; Grt, 石榴石; Mgs，菱镁矿; Omp，绿辉石; Pg, 钠云母; Phn, 多硅白云母; Rt, 金红石; Ttn I, 第一期榍石;

Ttn II, 第二期榍石; Zrn, 锆石

锆石包体, 由 LA-ICPMS 分析得到的 Zr 含量异常应是 由这些微粒锆石引起的, 而非前人认为的低温榴辉 岩-蓝片岩中局部 Zr 配分不平衡所致 ${ }^{[6,20]}$. 采样剖面 上发现的柯石英指示峰期金红石形成压力大于 2.7 $\mathrm{GPa}^{[12]}$ ，由金红石 $\mathrm{Zr}$ 温度计 ${ }^{[18]}$ 得到围岩榴辉岩在 2.7 $\mathrm{GPa}$ 压力时的峰期温度 $535 \sim 570^{\circ} \mathrm{C}$. 这一温度计略高 于用 Grt-Cpx 温度计以及相平衡模拟得到超高压榴辉 岩峰期温度 ${ }^{[11,12]}$. 榴辉岩和脉体中的金红石 $\mathrm{Zr}$ 含量 差别明显, 构成相对集中的两组数据. 脉体中的金红
石 $\mathrm{Zr}$ 含量比较集中, 单个颗粒平均值分别为 $55 \pm 7$, $66 \pm 6$ 和 $55 \pm 5 \mathrm{ppm}$. 除金红石外, 其他脉体矿物有角 闪石 (钠钙质)、绿帘石、石英、绿泥石、钠长石、白 色云母、方解石和榍石等低级变质矿物 ${ }^{[13]}$, 未见高压 特征矿物(如绿辉石). 金红石在绿帘角闪岩相压力条 件下 $\left(1.0 \mathrm{GPa}^{[11]}\right)$ 的结晶温度为 $530 \sim 540^{\circ} \mathrm{C}^{[13]}$. 由于 高压脉体往往受到绿帘角闪岩相或绿片岩相不同程 度的叠加改造作用(图 1(c)), 上述脉体中的角闪石和 钠长石等低压指示矿物很可能不与金红石共生, 它们 

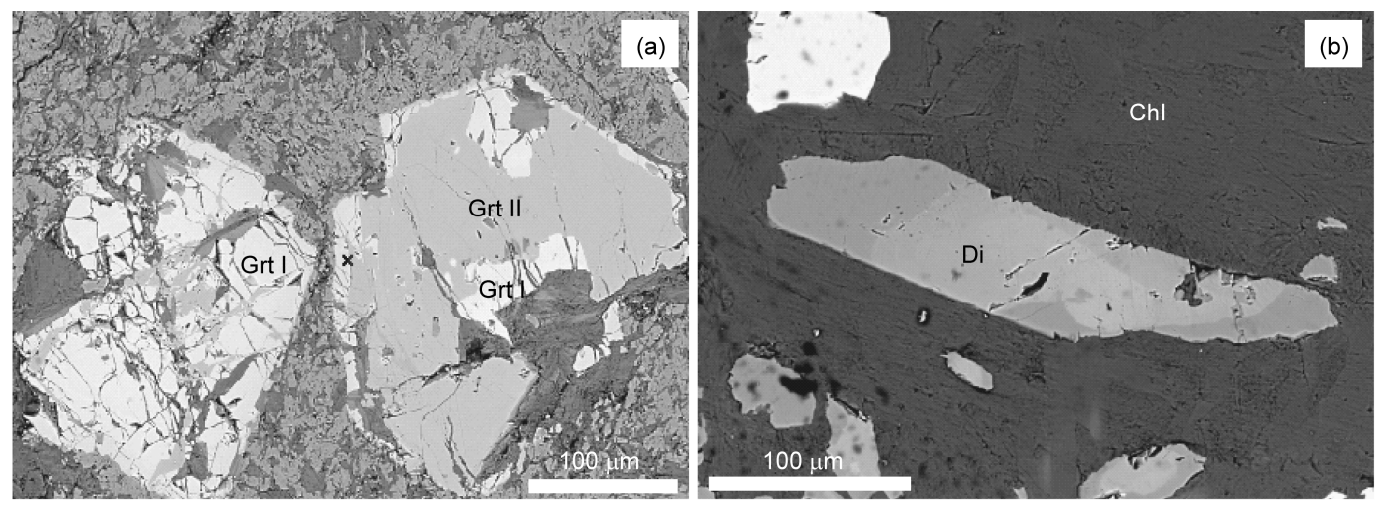

图 2 西天山异剥钙榴岩中的钙铝榴石、残余状铁铝榴石(a)和透辉石(b) 据文献[14]修改. Chl, 绿泥石; Di, 透辉石; Grt I, 铁铝榴石; Grt II, 钻铝榴石

是绿辉石退变质形成的.

Lü 等人 ${ }^{[12]}$ 根据高压脉体明显切穿围岩超高压榴 辉岩面理的现象, 认为高压脉体形成于峰期变质阶 段之后(折返阶段); 结合脉体金红石 $\mathrm{Zr}$ 含量温度计 以及特征脉体矿物组合绿辉石 + 钠云母+蓝闪石, 算 得高压脉体的形成条件为 $1.3 \sim 2.1 \mathrm{GPa}, 540 \sim 580^{\circ} \mathrm{C}$. 西天山高压脉体与围岩柯石英榴辉岩的野外接触关 系、矿物学特征以及温压条件的差异都表明, 低温/ 超高压变质岩在折返过程可以发生大规模的流体活 动和微量元素迁移, 这些流体活动反过来又有可能 进一步促进超高压地体的折返，有别于前人关于俯 冲进变质脱水的认识 ${ }^{[5,6,21]}$.

\section{3 异剥钙榴岩}

西天山长阿吾子地区的异剥钙榴岩是一种特殊 类型的异剥钙榴岩. 它们虽然与洋底变质作用成因 的异剥钙榴岩在产状和矿物组合方面很相似, 但其 原岩和形成机制却完全不同, 是由俯冲带榴辉岩经 异剥钙榴岩化作用形成 ${ }^{[22,23]}$. 蛇纹岩是由超基性岩 水化而成, 蛇纹岩化过程中单斜辉石分解, 形成富钙 流体，富钙流体交代基性岩石形成异剥钙榴岩. 因此, 蛇纹岩化和异剥钙榴岩化是同一地球化学过程的两 种表现. 西天山的异剥钻榴岩与蛇纹岩伴生, 呈环带 状, 由外向内依次是完全异剥钙榴岩化岩石, 部分异 剥钙榴岩化岩石(图 2(a), (b)) 和未异剥钙榴岩化岩石 (即基性榴辉岩, 已退变). 根据矿物组合的差异, 完 全异剥钙榴岩化岩石又可以分为葡萄石异剥钙榴岩, 水铝榴石-透辉石异剥䥻榴岩和符山石异剥钙榴岩. 异剥钙榴岩化开始的温压条件为 $370 \sim 410^{\circ} \mathrm{C}, 0.65 \sim$
$0.85 \mathrm{GPa}$, 大规模的异剥钙榴岩化出现在 $200 \sim 350^{\circ} \mathrm{C}$,

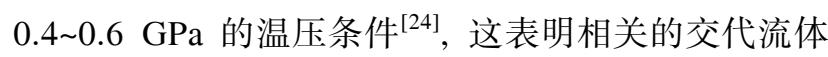
均来自俯冲带浅部. 锆石 U-Pb 定年得到两组年龄: $422 \pm 10$ 和 291 $\pm 15 \mathrm{Ma}$ (图 3), 前者代表蛇绿岩原岩形 成的时间, 后者代表蛇纹岩化和异剥钙榴岩化的时 间 ${ }^{[23]}$. 全岩微量元素特征表明, 退变榴辉岩原岩与 俯冲带环境相关, 代表俯冲上板片的岛弧环境 ${ }^{[24]}$.

为限定异剥钙榴岩化过程中的流体成分, 我们 对比了异剥钙榴岩化程度不同的 3 类岩石的主要矿 物成分, 全岩主量和微量元素成分特征 ${ }^{[14]}$. 在 $\mathrm{ACF}$ 图上, 随着异剥钻榴岩化程度的增加, 全岩成分从 $\mathrm{F}$ 端元向 $\mathrm{C}$ 端元演化, 代表 $\mathrm{Fe}$ 减少、 $\mathrm{Ca}$ 增加的趋势, 而且完全异剥钙榴岩成分落在了前人所做的异剥钻 榴岩成分范围内. 假设 $\mathrm{Al}$ 为不迁移元素, 根据 Grant ${ }^{[25]}$ 的计算方法绘制主量元素、微量元素和 REE 等浓度图, 发现异剥钙榴岩化过程中交代流体的成

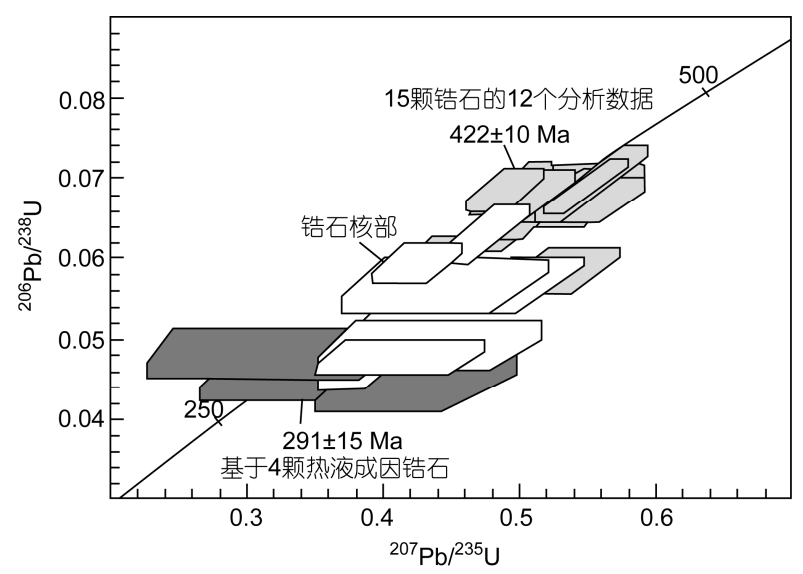

图 3 西天山异剥钙榴岩的锆石 U-Pb 年龄谐和图 据文献[23]修改 
分是复杂多变的：部分异剥钙榴岩化阶段流体富集 $\mathrm{Ca}, \mathrm{Si}, \mathrm{Ti}, \mathrm{Mn}, \mathrm{Nb}, \mathrm{Ta}, \mathrm{Zr}$ 和 $\mathrm{Hf}$, 亏损 $\mathrm{Fe}, \mathrm{Mg}, \mathrm{Na}, \mathrm{K}$, $\mathrm{REE}, \mathrm{Tb}$ 和 $\mathrm{Y}$; 完全异剥钙榴岩阶段, 流体富集 $\mathrm{Ca}$, $\mathrm{Mg}, \mathrm{LREE}, \mathrm{Ni}$ 和 $\mathrm{Cr}$, 亏损 $\mathrm{Fe}, \mathrm{Ti}, \mathrm{Rb}, \mathrm{Ba}, \mathrm{MREE}$ 和 HREE 等元素. 与洋底变质作用形成的异剥钙榴岩不 同, 西天山长阿吾子异剥钙榴岩形成过程中不活动
性高场强元素 $\mathrm{Ti}, \mathrm{Zr}, \mathrm{Hf}, \mathrm{Nd}$ 和 Ta 等元素都发生了明 显的迁移. 与蛇纹岩接触处的流体活动剧烈, 富水流 体相的强烈淋滤作用使大部分元素发生了迁移, 异 剥钙榴岩化作用比较彻底; 部分异剥钙榴岩化过程 中流体以渗透作用为主, 且不是完全饱和的, 形成不 平衡结构.

\section{参考文献}

1 Hermann J, Spandler C, Hack A, et al. Aqueous fluids and hydrous melts in high-pressure and ultra-high pressure rocks: Implications for element transfer in subduction zones. Lithos, 2006, 92: 399-417

2 Zheng Y F. Metamorphic chemical geodynamics in continental subduction zones. Chem Geol, 2012, 328: 5-48

3 Bebout G E, Agard P, Kobayashi K, et al. Devolatilization history and trace element mobility in deeply subducted sedimentary rocks: Evidence from Western Alps HP/UHP suites. Chem Geol, 2013, 342: 1-20

4 King R L, Bebout G E, Kobayashi K, et al. Ultrahigh-pressure metabasaltic garnets as probes into deep subduction zone chemical cycling. Geochem Geophys Geosyst, 2004, 5: Q12J14

5 Gao J, Klemd R. Primary fluids entrapped at blueschist to eclogite transition: Evidence from the Tianshan meta-subduction complex in northwestern China. Contrib Mineral Petrol, 2001, 142: 1-14

6 John T, Klemd R, Gao J, et al. Trace-element mobilization in slabs due to non steady-state fluid-rock interaction: Constraints from an eclogite-facies transport vein in blueschist (Tianshan, China). Lithos, 2008, 103: 1-24

7 John T, Gussone N, Podladchikov Y Y, et al. Volcanic arcs fed by rapid pulsed fluid flow through subducting slabs. Nat Geosci, 2012, 5: 489-492

8 Zack T, John T. An evaluation of reactive fluid flow and trace element mobility in subducting slabs. Chem Geol, 2007, 239: 199-216

9 Zhang L F, Ai Y L, Song S G, et al. A brief review of UHP meta-ophiolitic rocks, southwestern Tianshan, western China. Int Geol Rev, 2007, 49: 811-823

10 Lü Z, Zhang L F, Du J X, et al. Coesite inclusions in garnet from eclogitic rocks in western Tianshan, northwest China: Convincing proof of UHP metamorphism. Am Mineral, 2008, 93: 1845-1850

11 Lü Z, Zhang L, Du J, et al. Petrology of coesite-bearing eclogite from Habutengsu Valley, western Tianshan, NW China and its tectonometamorphic implication. J Metamorph Geol, 2009, 27: 773-787

12 Lü Z, Zhang L F, Du J X, et al. Petrology of HP metamorphic veins in coesite-bearing eclogite from western Tianshan, China: Fluid processes and elemental mobility during exhumation in a cold subduction zone. Lithos, 2012, 136-139: 168-186

13 Chen Z Y, Zhang L F, Du J X, et al. Zr-in-rutile thermometry in eclogite and vein from southwestern Tianshan, China. J Asian Earth Sci, 2013, 63: 70-80

14 申婷婷, 张立飞, 李旭平. 新疆西天山异剥钙榴岩地球化学特征及其对俯冲带流体的指示意义. 岩石学报, 2012, 28: 2235-2249

15 Manning C E. The chemistry of subduction-zone fluids. Earth Planet Sci Lett, 2004, 223: 1-16

16 Zheng Y F, Xia Q X, Chen R X, et al. Partial melting, fluid supercriticality and element mobility in ultrahigh-pressure metamorphic rocks during continental collision. Earth-Sci Rev, 2011, 107: 342-374

17 Lucassen F, Franz G, Dulski P, et al. Element and Sr isotope signatures of titanite as indicator of variable fluid composition in hydrated eclogite. Lithos, 2011, 121: 12-24

18 Tomkins H S, Powell R, Ellis D J. The pressure dependence of the zirconium-in-rutile thermometer. J Metamorph Geol, 2007, 25: 703-713

19 Zheng Y F, Gao X Y, Chen R X, et al. Zr-in-rutile thermometry of eclogite in the Dabie orogen: Constraints on rutile growth during continental subduction-zone metamorphism. J Asian Earth Sci, 2011, 40: 427-451

20 Beinlich A, Klemd R, John T, et al. Trace-element mobilization during Ca-metasomatism along a major fluid conduit: Eclogitization of blueschist as a consequence of fluid-rock interaction. Geochim Cosmochim Acta, 2010, 74: 1892-1922

21 Gao J, John T, Klemd R, et al. Mobilization of Ti-Nb-Ta during subduction: Evidence from rutile-bearing dehydration segregations and veins hosted in eclogite, Tianshan, NW China. Geochim Cosmochim Acta, 2007, 71: 4974-4996

22 Li X P, Zhang L, Wei C, et al. Petrology of rodingite derived from eclogite in western Tianshan, China. J Metamorph Geol, 2007, 25: 363-382

23 Li X P, Zhang L F, Wilde S A, et al. Zircons from rodingite in the Western Tianshan serpentinite complex: Mineral chemistry and U-Pb ages define nature and timing of rodingitization. Lithos, 2010, 118: 17-34

24 李旭平, 张立飞, 王泽利. 西天山异剥钙榴岩的地球化学研究. 岩石学报, 2008, 24: 711-717

25 Grant J A. The isocon diagram: A simple solution to Gresens' equation for metasomatic alteration. Econ Geol, 1986, 81: 1976-1982 